\title{
THE PERCEPTION OF THE IMPACT CAUSED BY VIOLENCE DISCLOSURE ON RAPE VICTIMS' SUPPORT NETWORK
}

Maria Teresa Ferreira Cortes, Tatiane Maria Angelo Catharini, Thais Miwa Taira, Claudia Oliveira Facuri, Otávio Prado Alabarse, Arlete Maria dos Santos Fernandes, Maria Eduardo Costa Pereira and Renata Cruz Soares de Azevedo.

Department of Medical Psychology and Psychiatry, School of Medical Sciences, State University of Campinas, Brazil

\section{Background}

Violence against women is a worldwide public health problem and rape is one of its most brutal manifestations. ${ }^{1}$ After being raped, it is very common for women turn to other people looking for help. ${ }^{2}$ More often they look for informal support providers and at least one third of the victims receive negative reactions. ${ }^{3-4}$

\section{Objectives}

The aim of this work is to present and discuss the perceptions of rape victims about their support network.

\section{Materials and methods}

The data here presented are partial results of a study designed as an interpretive descriptive study with nonprobability sampling. Patients participated in an individual semi-structured interview related to their experiences of rape and the importance of having a family network. This work was developed on a referral center for sexual violence at Prof. Dr. José Aristodemo Pinotti Women's Hospital, at the State University of Campinas, in Brazil.

\section{Results}

All patients reported the act of disclosure as an important part of their recovering process. However some patients were afraid to harm their families by disclosuring to them.

"I was afraid to tell my mother, because something could happen to her heart. I thought she would panic." (patient 8)

"I couldn't tell him (her brother). It doesn't mean that I don't trust him, but I don't want to hurt him". (patient 10)
Many described the perception that their beloved ones were not prepared to offer full support. Some even described that their support providers developed symptoms of extreme sadness and anxiety.

\section{"She didn't know what to do... she didn't know.. she is 24 years old I can understand it... she didn't know what to do" (patient 1)}

\begin{abstract}
"I always tell her (her mother) that I understand it. Is difficult for her, but it happened to me and she must understand it." (patient 2)
\end{abstract}

"Sometimes you tell a friend and he reacts by saying 'it sucks'. Yes, it does, I know, are we going to do anything about that? What are we going to do?" (patient 4)

\section{Discussion and Conclusions}

The support network is an important element of the recovering process of rape victims and it is already well established that the act of disclosure may provide many benefits to victims, such as emotional and medical support. ${ }^{5}$ On the other hand, literature reveals that it is very unlikely that informal support providers are more poised than rape survivors to experience disclosure and, although they want to be helpful, they lack knowledge or confidence to provide effective support to victims. ${ }^{6-8}$

Therefore it is fundamental that informal support providers are included in the treatment of rape victims, being instructed on how to offer appropriate emotional help and receiving professional mental care, when in need.

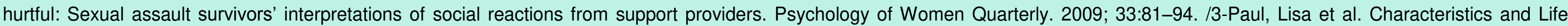

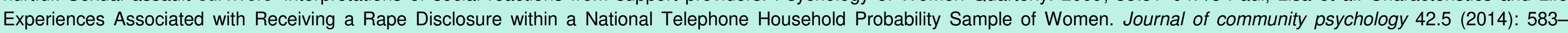

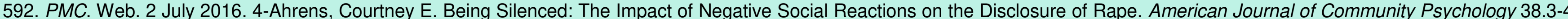

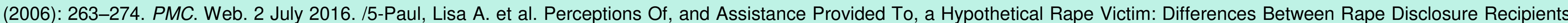

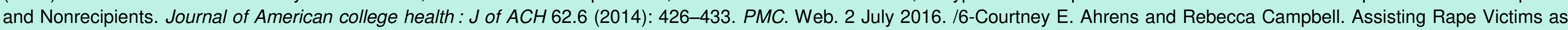

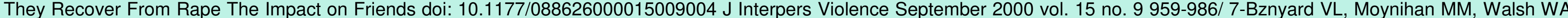

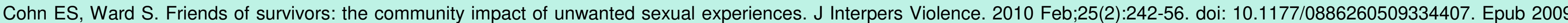

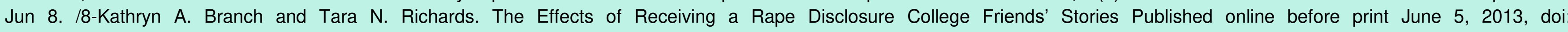
$10.1177 / 1077801213490509$ Violence Against Women May 2013 vol. 19 no. 5 658-670 